\title{
Redução de custos logísticos e lead time em operações de comércio exterior com a utilização do custeio baseado em atividades - ABC: Uma pesquisa-ação
}

\author{
Fábio Hiroshi Tomoyose \\ Mestrado em Administração pela Universidade Municipal de São Caetano do Sul - \\ USCS \\ Av. Goiás, 3400. Barcelona. São Caetano do Sul/SP. CEP: 09550-051 \\ E-mail:hiroshi_fabio@hotmail.com
}

Ana Cristina de Faria

Doutorado em Controladoria e Contabilidade pela Universidade de São Paulo - USP

Professora na Universidade Municipal de São Caetano do Sul - USCS

Av. Goiás, 3400. Barcelona. São Caetano do Sul/SP. CEP: 09550-051

E-mail: anacfaria@uscs.edu.br

Paulo Sérgio Lopes Ruiz Mestrado em Administração pela Universidade Municipal de São Caetano do Sul -

USCS

Professor na Universidade Municipal de São Caetano do Sul - USCS Av. Goiás, 3400. Barcelona. São Caetano do Sul/SP. CEP: 09550-051

E-mail:p.ruiz@uol.com.br

\section{RESUMO}

Este estudo tem como objetivo verificar como podem ser reduzidos os custos logísticos e o lead-time nas operações de importação e exportação, dispondo dos recursos disponíveis e sem qualquer tipo de investimento. Por meio de pesquisa-ação em empresa do segmento de papelaria, com a aplicação do Custeio Baseado em Atividades - ABC houve a necessidade de uma análise das atividades e dos custos, e a definição exata dos direcionadores, bem como pleno conhecimento da influência de determinados custos em outros. Como resultado obteve-se uma redução de 21 dias de lead time e de $43 \%$ nos custos logísticos nas exportações. Em relação às importações houve mudança total da configuração originalmente empregada pela Nippon2, que obteve reduções com a aplicação do $\mathrm{ABC}$. As mudanças não ocasionaram trade-offs; mas sim efetivas reduções de custos e lead time, sem qualquer necessidade de investimentos.

Palavras-Chave: Custeio Baseado em Atividades - ABC. Custos Logísticos. Exportação. Importação. Lead Time. 
Redução de custos logísticos e lead time em operações de comércio exterior com a utilização do custeio baseado em atividades - ABC: Uma pesquisa-ação

Fábio Hiroshi Tomoyose, Ana Cristina de Faria, Paulo Sérgio Lopes Ruiz

\section{ABSTRACT}

This study objective to verify how the logistic costs and lead time in import and export operations can be reduced, using available resources and without any type of investment. Through a Research-action in a company from stationery goods segment by the application of Activity Based Costing - ABC it was needed an analysis of activities and costs, besides the accurate cost drivers definition, as well as full knowledge of the influence of certain costs in others. As a result, there was obtained reduction of 21 days of lead time and $43 \%$ in the logistic costs in the export. Regarding the import operations the configuration originally used by the Nippon2 was totally changed, which got reductions by the application of the ABC. Changes did not cause trade-offs; but effective costs and lead times reduction, without any further investments.

Keywords: Activity Based Costing - ABC. Logistic costs. Export. Import. Lead Time.

\section{INTRODUÇÃO}

Com as economias cada vez mais globalizadas e o aumento contínuo da competitividade entre países e organizações, verifica-se a busca incansável destas por métodos e controles capazes de promover a perfeita alocação de recursos, eliminar desperdícios e re-trabalhos, reduzir custos ou até mesmo eliminá-los. Kotabe e Helsen (2009) argumentam que os avanços nos elementos estruturais no comércio internacional abrem espaço para inovações e mudanças na estratégia de suprimentos devido ao aumento do número de gerentes de compras experientes em suprimento, as melhorias no transporte e nas comunicações e as instalações de produção espalhadas pelo mundo, ou seja, as empresas globalmente orientadas.

A necessidade de importações decorre da escassez da matéria-prima ou material secundário. Apesar de o Brasil ser um país rico em recursos minerais, existe a necessidade de importar outros produtos extrativos. Outras vezes, isso ocorre em razão da precária tecnologia associada à montagem do equipamento adequado, responsável pela agregação do serviço ao produto. Outra razão para empresas importarem é estar em contato com empresas que detêm tecnologia de ponta e, desta forma, estar atualizadas frente às inovações do mercado. 
Redução de custos logísticos e lead time em operações de comércio exterior com a utilização do custeio baseado em atividades - ABC: Uma pesquisa-ação

Fábio Hiroshi Tomoyose, Ana Cristina de Faria, Paulo Sérgio Lopes Ruiz

Lopez e Gama (2002) apresentam como principais razões para a internacionalização o aprimoramento da qualidade, a incorporação de tecnologia, a redução do custo de produção e a aquisição de novas ideias que possibilitem o crescimento empresarial. Kotabe e Helsen (2009) afirmam que a habilidade de entregar um volume elevado de produtos de qualidade satisfatória a preço razoável tem sido um marco de muitas empresas. O mercado internacional apresenta a necessidade de mudanças estratégicas de preço e quantidade para qualidade e confiabilidade de produtos, sendo esta nova estratégia determinante na comercialização.

É primordial a união de esforços e a busca contínua pelo aprimoramento e desenvolvimento de técnicas capazes de conduzir as organizações a um nível máximo de eficiência e eficácia, de tal forma que os processos e atividades por ela desempenhados possam gerar valor percebido aos seus clientes, garantindo a perpetuação dos mesmos, bem como vantagem competitiva perante a concorrência, principalmente em nível global. Para Keegan e Green (2000, p.4), as empresas que conseguem criar mais valor aos seus clientes em relação aos seus concorrentes, são dotadas de vantagem competitiva no mercado em que atuam. Isso inclui a redução de seus custos e redução de lead times.

$\mathrm{Na}$ opinião de Bowersox, Closs e Cooper (2002, p.180), as operações globais aumentam os custos logísticos, o lead time e a complexidade. Lambert et al. (1998, p.13) comentam que "se uma empresa proporciona produtos ao cliente rapidamente a um custo baixo, como resultado de eficiência em logística, pode ganhar vantagens de fatia de mercado em relação aos concorrentes".

Nesse sentido, esta pesquisa partiu do seguinte questionamento: Como podem ser reduzidos os custos logísticos e o lead-time nas operações de importação e exportação, dispondo dos recursos disponíveis e sem qualquer tipo de investimento? $\mathrm{Na}$ pesquisa bibliográfica realizada, encontrou-se um número relativamente pequeno e limitado de publicações, em face da problemática e o ensejo das organizações no alcance máximo da eficiência e a consequente redução de custos, eliminação de desperdícios e redução do lead-time. Este trabalho, para responder à sua questão de 
Redução de custos logísticos e lead time em operações de comércio exterior com a utilização do custeio baseado em atividades - ABC: Uma pesquisa-ação

Fábio Hiroshi Tomoyose, Ana Cristina de Faria, Paulo Sérgio Lopes Ruiz pesquisa, tem como objetivo verificar como podem ser reduzidos os custos logísticos e - lead-time nas operações de importação e exportação, dispondo dos recursos disponíveis e sem qualquer tipo de investimento.

Este artigo está dividido em quatro partes principais, além desta Introdução, a saber: a base conceitual que permite a identificação da sistemática dos processos de importação e exportação e o método do custeio baseado em atividades; os aspectos metodológicos empregados na pesquisa; o desenvolvimento da pesquisa-ação; a análise dos resultados da pesquisa e a apresentação das conclusões.

\section{PLATAFORMA TEÓRICA}

\subsection{Processos Logísticos de Importação e Exportação}

O conhecimento pormenorizado das atividades inerentes às importações e às exportações é de fundamental importância para que as variáveis que influenciam o custo e o lead-time sejam identificadas e tornem-se controláveis. De acordo com Fender et al. (2000), a logística internacional envolve quatro diferenças significantes em comparação às operações nacionais ou mesmo as regionais, a saber: distância; complexidade dos documentos exigidos pelas autoridades; diversidade das práticas, o ambiente operacional local e as variações culturais.

$\mathrm{Na}$ opinião de Bowersox, Closs e Cooper (2002, p.24), os princípios da logística e os ideais de integração da cadeia de suprimentos são os mesmos tanto globalmente quanto domesticamente; porém as diferenças mencionadas entre as logísticas nacionais e internacionais tornam o ambiente operacional mais complexo e oneroso. Para Wood et al. (2002, p. 309), a logística internacional é um sistema na qual o fluxo de documentos é tão importante quanto o fluxo de produtos.

A importação compreende a entrada temporária ou definitiva em território nacional de bens originários ou procedentes de outros países; observadas as normas comerciais, cambiais e fiscais vigentes (MDIC, 2013). Carbaugh (2004, p.11) comenta o equívoco da mídia e de políticos na afirmação de que as exportações são melhores 
Redução de custos logísticos e lead time em operações de comércio exterior com a utilização do custeio baseado em atividades - ABC: Uma pesquisa-ação

Fábio Hiroshi Tomoyose, Ana Cristina de Faria, Paulo Sérgio Lopes Ruiz

para o país do que as importações; pois comprometem a indústria nacional, a balança comercial e a geração de empregos. A exportação, por sua vez, é a saída da mercadoria do território aduaneiro, decorrente de um contrato de compra e venda internacional, que pode ou não resultar na entrada de divisas (MDIC, 2013). Na teoria clássica do comércio internacional, pode-se encontrar, por meio do princípio das vantagens comparativas, formulado por David Ricardo em 1817, as premissas para o aumento do grau de competitividade, que sugere que cada país deva especializar-se na produção daquela mercadoria em que é relativamente mais eficiente, ou que incorra em custo relativamente menor (VASCONCELLOS, 2000, p.345).

O conhecimento da sistemática do comércio exterior é de fundamental importância na busca pela redução de custos e lead-time, e a consequente obtenção de vantagem competitiva por meio de operações eficientes. Cabe destacar a importância dos Incoterms (Termos Internacionais de Comércio), que estabelecem as responsabilidades entre o comprador e o vendedor dentro da estrutura de um contrato internacional de compra e venda, de acordo com Rodrigues (2003, p.29). Conforme Faria e Costa (2005, p.144), a definição do Incoterm a ser utilizada impacta os Custos Logísticos, pois definem os direitos e obrigações mínimas do vendedor e do comprador, ou seja, define todos os custos logísticos da operação.

Outro fator relevante e de grande importância é o conhecimento dos documentos empregados nas Importações e Exportações. De maneira geral, existem os documentos comuns tanto às importações quanto às exportações, e os específicos para cada operação. Os documentos comuns são a Proforma Invoice (Pré-Fatura); Commercial Invoice (Fatura Comercial); Packing List (Romaneio de Embarque); Air Way Bill (Conhecimento de Transporte Aéreo) no caso de embarques aéreos e Bill of Lading (Conhecimento de Transporte Marítimo), no caso de embarques marítimos. Os documentos específicos são o RE (Registro de Exportação) e a DE (Declaração de Exportação) no caso das exportações, e DI (Declaração de Importação) e a LI (Licença de Importação), no caso das Importações (ROCHA, 2008). 
Redução de custos logísticos e lead time em operações de comércio exterior com a utilização do custeio baseado em atividades - ABC: Uma pesquisa-ação

Fábio Hiroshi Tomoyose, Ana Cristina de Faria, Paulo Sérgio Lopes Ruiz

O despacho aduaneiro de mercadorias na exportação é o procedimento fiscal mediante o qual é verificada a exatidão dos dados declarados pelo exportador em relação às mercadorias, aos documentos apresentados e à legislação específica, com vistas a seu desembaraço e a sua saída para o exterior. Segundo Maluf (2003, p. 204), o despacho aduaneiro de mercadorias na importação é o procedimento mediante o qual é verificada a exatidão dos dados declarados pelo importador em relação às mercadorias importadas, aos documentos apresentados e à legislação específica, com vistas ao seu desembaraço aduaneiro. Constitui o ato final do despacho aduaneiro, em virtude do qual é autorizada a entrega da mercadoria ao importador. Todo esse fluxo de processos de importação e exportação deve ser mensurado, e o método de custeio aconselhável para realizar essa mensuração é o Custeio Baseado em Atividades - ABC.

\subsection{Custeio Baseado em Atividades - ABC}

O Custeio Baseado em Atividades - ABC é um método de custeio utilizado para apropriar os custos por meio das atividades executadas dentro da empresa. Esse método procura reduzir as distorções provocadas pelo rateio arbitrário dos custos indiretos, e tem como objetivo auxiliar na gestão de custos devido às amplas informações fornecidas para o nível gerencial da empresa (HORNGREN; FOSTER; DATAR, 2000).

$\mathrm{O} A B C$ é essencial para a implantação de um projeto ao se definir alguns itens como: custeio de produtos e serviços; inclusão ou não de gastos com vendas e administração no custo dos produtos e serviços; custeio de canais de distribuição; custeio de clientes, mercados e segmentos de mercado; análise de lucratividade desses objetos custeados, com a utilização de custos históricos ou predeterminados (KAPLAN, 1998; ATKINSON et al., 2000).

$\mathrm{Na}$ opinião de Bornia (2002, p.121) o fundamento do $A B C$ reside em identificar "os custos das várias atividades da empresa, e entender seu comportamento, encontrando bases que representem as relações entre os produtos e essas atividades". Este método contempla um rastreamento de dados que, habitualmente, não são 
Redução de custos logísticos e lead time em operações de comércio exterior com a utilização do custeio baseado em atividades - ABC: Uma pesquisa-ação

Fábio Hiroshi Tomoyose, Ana Cristina de Faria, Paulo Sérgio Lopes Ruiz

considerados nos sistemas de custeio tradicionais, e por extensão auxilia a redimensionar a mentalidade gerencial das empresas em que é aplicado.

Faria e Costa (2005, p. 258) consideram que este método mensura os custos dos produtos e serviços por meio de processos, atividades e tarefas que consomem os recursos, e que são distribuídos pelos direcionadores de custo. Martins (2003) comenta que o direcionador de custos é o fator que determina a ocorrência de uma atividade. Como essas atividades exigem recursos para ser realizadas, o direcionador é o agente causador dos custos. Dessa forma, esse direcionador deve refletir a causa básica da atividade e, consequentemente, da existência de seus custos. Assim, o método ABC relaciona os custos com as atividades que consomem estes recursos e, posteriormente, apropria os custos das referidas atividades aos diversos objetos.

Para a aplicação do método ABC em processos logísticos, Faria e Costa (2005, p. 268) estabelecem a seguinte lógica: verificação dos processos/atividades ou subatividades existentes (mapeamento); análise das características e especificidades dos referidos processos/atividades ou tarefas; bem como seus fluxos físicos e de informações; identificação dos recursos consumidos (custos) em cada um dos processos/atividades ou sub-atividades, com base em informações contábil-gerenciais; identificação, minimização e eliminação de ineficiências, retrabalhos, desperdícios, capacidades mal dimensionadas etc.; definição dos direcionadores de recursos dos referidos custos para alocação aos processos/atividades ou sub-atividades; definição dos objetos de custeio e definição dos direcionadores de atividades dos referidos custos para alocação aos objetos (produtos, serviços, clientes etc.).

A própria representação dos processos custeados, já que estes são mapeados para a identificação das atividades executadas, pode ser considerada como uma das vantagens da aplicação do $A B C$. Esse mapeamento pode ser restrito a uma área ou processo de interesse do levantamento de custos, ou pode ser feito para a empresa como um todo. A partir do mapeamento a empresa terá um quadro das atividades executadas, que poderá propiciar ações corretivas para melhorar os serviços e minimizar os custos relacionados. Pode-se citar a identificação de atividades 
Redução de custos logísticos e lead time em operações de comércio exterior com a utilização do custeio baseado em atividades - ABC: Uma pesquisa-ação

Fábio Hiroshi Tomoyose, Ana Cristina de Faria, Paulo Sérgio Lopes Ruiz

redundantes ou repetidas, que aumentam os custos desnecessariamente. De acordo com Themido et al. (2000), a análise de atividades pode identificar oportunidades para reduzir os custos operacionais ou melhorar o desempenho dos serviços.

\section{ASPECTOS METODOLÓGICOS}

Nesse estudo empregou-se como metodologia a Pesquisa-Ação em uma empresa multinacional japonesa que atua no segmento de papelaria e que será tratada como Nippon2 por solicitação da empresa. Esta organização é estabelecida na cidade de São Paulo, e tem a intenção de tornar-se líder no mercado latino americano de produtos para papelaria. Recorreu-se, inicialmente, à pesquisa bibliográfica no sentido de identificar os subsídios necessários a responder à questão norteadora e buscar o arcabouço para atender ao objetivo deste trabalho.

Na opinião de Thiollent (2000, p. 14), a Pesquisa-Ação pode ser definida como

um tipo de pesquisa com base empírica que é concebida e realizada em estreita associação com uma ação ou com a resolução de um problema coletivo e na qual os pesquisadores e participantes representativos da situação ou do problema estão envolvidos de modo cooperativo e participativo.

Martins (2006, p. 47), por sua vez, comenta que

a Pesquisa-Ação (PA) consiste essencialmente em acoplar pesquisa e ação em um processo no qual os atores implicados participam junto com o pesquisador, para chegarem interativamente a elucidar uma questão da realidade em que estão inseridos, identificando problemas coletivos, buscando e experimentando soluções em situação real. Simultaneamente, há produção e uso de conhecimento.

No intuito de desenvolver a pesquisa, buscou-se empresa cujos gestores dos 
Redução de custos logísticos e lead time em operações de comércio exterior com a utilização do custeio baseado em atividades - ABC: Uma pesquisa-ação

Fábio Hiroshi Tomoyose, Ana Cristina de Faria, Paulo Sérgio Lopes Ruiz

Departamentos de Logística e Comércio Exterior tivessem como foco a melhoria da gestão de seus custos logísticos em processos de importação e exportação. Esses gestores deveriam envolver-se ativamente na pesquisa, de modo cooperativo e participativo com os pesquisadores, tal como preconiza a filosofia da Pesquisa-Ação. De acordo com Richardson (2007), este pode ser considerado um estudo de natureza descritiva; já que pretende, por meio da Pesquisa-Ação, descrever quais os recursos, as atividades e seus custos, inerentes aos processos logísticos do importação e exportação e como os custos podem ser reduzidos. Para realizar a mensuração de custos foi empregado o método do Custeio Baseado em Atividades, que é adequado na mensuração dos custos de operações logísticas (FARIA; COSTA, 2005).

Os procedimentos de coleta de dados iniciaram-se em Janeiro de 2009 e duraram até Agosto do mesmo ano. Neste período, além das entrevistas estruturadas com os gestores da empresa analisada, foram feitas observações diretas dos processos e atividades realizadas, bem como pesquisas documentais, contemplando informações contábil-gerenciais, entre outros documentos disponibilizados pelos gestores. $\mathrm{Na}$ sequência, o desenvolvimento da pesquisa.

\section{PESQUISA AÇÃO NA EMPRESA NIPPON2}

\subsection{As exportações aéreas da Empresa Nippon2}

A empresa resolveu avaliar seus custos logísticos pertinentes as suas operações de exportação, em uma tentativa de reduzi-los ao seu nível mínimo possível, viabilizando ou o repasse dessa redução ao preço do produto final ou o aumento da margem de lucro. Diante deste desafio, o gestor responsável deu início à identificação dos custos inerentes às exportações da empresa para a América Latina, tendo sido levantados todos os processos realizados. Durante a avaliação foi verificada uma diversidade muito grande entre os processos, de tal forma que uma avaliação conjunta poderia direcionar a administração a decisões falhas ou imprecisas. Dessa forma, em um primeiro momento optou-se pela generalização da redução de custos, ou seja, 
Redução de custos logísticos e lead time em operações de comércio exterior com a utilização do custeio baseado em atividades - ABC: Uma pesquisa-ação

Fábio Hiroshi Tomoyose, Ana Cristina de Faria, Paulo Sérgio Lopes Ruiz

independentemente da variedade de operações e produtos exportados, o gerente responsável deveria aplicar uma metodologia capaz de abranger todas as operações. Face este desafio, foi possível estabelecer um padrão entre as exportações marítimas e aéreas, sendo este último o foco deste estudo para as exportações.

O primeiro passo da avaliação foi o mapeamento das atividades e do fluxo de informações inerentes às exportações aéreas realizadas pela Nippon2, em que foram verificadas 40 atividades distribuídas entre o exportador, o representante legal, o agente de cargas, a transportadora, a corretora de câmbio e o Banco, somando um total de 1820 minutos, ou 30 horas e 20 minutos, para a realização das atividades; e um total de 119 dias, contados a partir do recebimento do pedido de compra até o recebimento das divisas, para fechamento do processo da exportação aérea. Foi considerado na pesquisa o período de 90 dias contados da data do embarque para a realização do pagamento (Recebimento da Ordem de Pagamento vinda do exterior). Em uma segunda avaliação, considerando os custos, foram apuradas no período préembarque as seguintes informações:

Tabela 1 - Período Pré-Embarque (modelo tradicional)

\begin{tabular}{|c|c|c|c|c|c|c|c|}
\hline Executor & Atividades & Dias & Min.gastos & $\begin{array}{l}\text { Horas } \\
\text { gastas }\end{array}$ & Direcionador & $\begin{array}{c}\text { Custo } \\
\text { direto } R \$\end{array}$ & Custo \\
\hline$E$ & 16 & \multirow[t]{4}{*}{12} & 545 & $9 \mathrm{hrs} \mathrm{05min}$ & Hora trabalho & 174,31 & Variável \\
\hline $\mathrm{R}$ & 6 & & 455 & 7hrs 35min & processo/Exp. & 750,00 & Fixo \\
\hline$A$ & 3 & & 70 & $1 \mathrm{hrs} 10 \mathrm{~min}$ & processo/Exp. & 400,00 & Fixo \\
\hline$T$ & 3 & & 440 & $7 \mathrm{hrs} \mathrm{20min}$ & Peso & 500,00 & Variável \\
\hline Total & 28 & 12 & 1510 & $28 \mathrm{hrs} 50 \mathrm{~min}$ & & $1.824,31$ & \\
\hline
\end{tabular}

Fonte: Dados da Pesquisa (2009).

O Exportador (E) é responsável por $57,14 \%$ das atividades pré-embarque, sendo $36,09 \%$ do tempo gasto alocado para a efetivação das mesmas. Supondo que o analista responsável por estas atividades trabalhe 9 horas por dia, de segunda à sextafeira, 22 dias por mês e o seu custo para a empresa gire em torno de $R \$ 3.800,00$ mensais, conclui-se que o custo desta mão-de-obra, para cada exportação no período pré-embarque é de $R \$ 174,31$, ou seja, são despendidos $R \$ 19,19$ por hora trabalhada. 
Redução de custos logísticos e lead time em operações de comércio exterior com a utilização do custeio baseado em atividades - ABC: Uma pesquisa-ação

Fábio Hiroshi Tomoyose, Ana Cristina de Faria, Paulo Sérgio Lopes Ruiz

Nesta análise, define-se como direcionador de custos as horas trabalhadas e o custo da mão-de-obra como variável.

O Representante legal $(R)$ é responsável por $21,43 \%$ das atividades no período pré-embarque, sendo que $30,13 \%$ do tempo gasto são alocados para a efetivação das mesmas. O custo direto e fixo de $R \$ 750,00$, independentemente do tempo trabalhado, representa $41,11 \%$ do custo por desembaraço aduaneiro da exportação realizada. As atividades do agente de cargas (A) são responsáveis por 10,71\% das atividades de préembarque; sendo $4,64 \%$ do tempo gasto alocado para a efetivação das mesmas. $O$ direcionador definido neste caso é a quantidade de exportações ou desembaraços realizados.

O valor para a renumeração dos serviços aéreo-portuários e do agente de carga foi de $R \$ 400,00$ e representa $21,93 \%$ do custo total. Neste caso, os custos podem ser classificados como fixos e o direcionador como a quantidade de exportações realizadas, visto que o frete neste caso é pago pelo importador, e as tarifas incidentes são comuns a embarques com a configuração apresentada. A Transportadora (T), por sua vez, é responsável por $10,71 \%$ das atividades pré-embarque, sendo $29,14 \%$ do tempo gasto são alocados para a efetivação das mesmas.

A remuneração pelo transporte foi de $R \$ 500,00$ e representa $27,41 \%$. Nesta situação, o direcionador definido para avaliação é o peso bruto total carregado pela transportadora e o custo direto definido como variável. Os totais verificados no período pré-embarque, em que foram realizadas 28 atividades em 12 dias, alocados em 1510 minutos, perfazendo um montante de 28 horas e 50 minutos, consumindo $\mathrm{R} \$ 1.824,31$, classificados em custos diretos fixos e variáveis conforme descritos na Tabela 1. No período pós-embarque, os seguintes custos foram apurados, conforme Tabela 2, a seguir: 
Redução de custos logísticos e lead time em operações de comércio exterior com a utilização do custeio baseado em atividades - ABC: Uma pesquisa-ação

Fábio Hiroshi Tomoyose, Ana Cristina de Faria, Paulo Sérgio Lopes Ruiz

Tabela 2 - Período Pós-Embarque (modelo tradicional)

\begin{tabular}{|c|c|c|c|c|c|c|c|}
\hline Executor & Atividades & Dias & Min.gastos & $\begin{array}{l}\text { Horas } \\
\text { gastas }\end{array}$ & Direcionador & $\begin{array}{c}\text { Custo } \\
\text { direto } R \$\end{array}$ & Custo \\
\hline$E$ & 7 & \multirow[t]{4}{*}{107} & 190 & $3 \mathrm{hrs} \mathrm{10min}$ & Hora trabalho & 60,77 & Variável \\
\hline $\mathrm{R}$ & 1 & & 30 & $30 \mathrm{~min}$ & Processo/Exp. & - & Fixo \\
\hline C & 3 & & 80 & $1 \mathrm{hrs} 20 \mathrm{~min}$ & Valor FOB. & 100,00 & Variável \\
\hline B & 1 & & 10 & $10 \mathrm{~min}$ & $\begin{array}{l}\text { Taxa por } \\
\text { Operação }\end{array}$ & 100,00 & Fixo \\
\hline Total & 12 & 107 & 310 & $5 \mathrm{hrs} 10 \mathrm{~min}$ & & 260,77 & \\
\hline
\end{tabular}

Fonte: Dados da Pesquisa (2009).

No período de pós-embarque, o Exportador (E) é responsável por 58,33\% das atividades, sendo $61,29 \%$ do tempo gasto alocado para a efetivação das mesmas. $O$ custo direto das horas despendidas gira em torno de $23,30 \%$ e foram definidos como direcionadores de custos, as horas trabalhadas e o custo da mão-de-obra é variável. $\mathrm{O}$ Representante legal $(R)$ é responsável por $8,33 \%$ das atividades pós-embarque, sendo que $9,68 \%$ do tempo gasto são alocados para a efetivação das mesmas. O custo para cada exportação no período pós-embarque foi de $R \$ 60,77$. Neste período, definem-se como direcionadores de custos, as horas trabalhadas e o custo da mão-de-obra como variável. O custo da utilização de um representante legal no período pós-embarque não é mencionado, em função de sua representação como custo direto e fixo, já mensurado na Tabela 1.

A corretora de câmbio (C) é responsável por $25 \%$ das atividades pós-embarque, sendo que $25,81 \%$ do tempo gasto são alocados para a efetivação das mesmas. O valor para a renumeração para este serviço representa $R \$ 100,00(38,35 \%)$. Neste caso, o direcionador definido para avaliação é o percentual de $0,5 \%$ sobre o valor Free on Board - FOB em Reais da mercadoria, sendo o custo definido como direto e variável. O Banco (B) é responsável por 8,33\% das atividades pós-embarque, sendo que a remuneração representada para este serviço é de 38,35\%. Neste caso, o direcionador definido para avaliação é a taxa fixa por operação, ou seja, $R \$ 100,00$ por operação, sendo o custo definido como direto e fixo. Verificou-se no período pós-embarque que foram realizadas 12 atividades em 107 dias, considerando 90 dias do prazo para 
Redução de custos logísticos e lead time em operações de comércio exterior com a utilização do custeio baseado em atividades - ABC: Uma pesquisa-ação

Fábio Hiroshi Tomoyose, Ana Cristina de Faria, Paulo Sérgio Lopes Ruiz

recebimento das divisas, alocadas em 310 minutos, ou 5horas e 10 minutos, consumindo $\mathrm{R} \$ 260,77$ em custos diretos fixos e variáveis.

$\mathrm{Na}$ apuração dos custos logísticos totais da operação, considerando os períodos pré e pós-embarque, verificou-se o total de $R \$ 2.085,08$ para cada exportação aérea realizada; valor este utilizado como parâmetro na redução do custo total. A aplicação de uma nova metodologia deveria forçar o resultado dos custos das próximas exportações a um nível inferior ao verificado antes da aplicação do método $A B C$.

Os custos de exportação evidenciados nas Tabelas 1 e 2 compreendem, respectivamente, componentes que fazem parte do pré-embarque e pós-embarque. Neste cenário são envolvidos os tributos que podem oferecer créditos que, eventualmente, em casos específicos, podem ser recuperáveis. No tópico a seguir, são contemplados os custos logísticos de um modelo proposto, tanto para o pré-embarque quanto para o pós- embarque e o impacto destes na ação de redução de custos logísticos e do lead-time.

\subsection{Método de Custeio aplicado para redução dos custos logísticos nas exportações aéreas da empresa Nippon2}

Com base as informações obtidas, o gestor responsável, diante do desafio da aplicação de um método capaz de reduzir custos, dispondo dos recursos disponíveis, sem qualquer tipo de investimento que pudesse caracterizar-se em um novo custo, decidiu pela aplicação do método do Custeio Baseado em Atividades (ABC).

Com base na metodologia do $A B C$, como visto inicialmente, o gestor responsável, inicialmente procedeu ao mapeamento de todas as atividades, dispondoas em ordem cronológica, identificando cada executor, estabelecendo uma relação de tempo e atividade. Posteriormente, identificou os custos e os respectivos direcionadores, alocando-os a cada responsável pela execução das atividades, requisitos básicos para a aplicação do método $A B C$.

Diante da busca inicial da relação de causa e efeito dos custos inerentes às exportações aéreas da Nippon2, foi possível desenvolver uma nova metodologia para a 
Redução de custos logísticos e lead time em operações de comércio exterior com a utilização do custeio baseado em atividades - ABC: Uma pesquisa-ação

Fábio Hiroshi Tomoyose, Ana Cristina de Faria, Paulo Sérgio Lopes Ruiz

realização dessas mesmas operações, com a verticalização de atividades antes realizadas pelo representante legal e pela corretora de câmbio, tais como a confecção de REs (Registros de Exportação) e DDEs (Declaração de Despacho de Exportação), bem como a negociação de taxas de câmbio com o Banco. Verificou-se que as atividades, caso desempenhadas pelo próprio exportador e o agente de cargas seriam mais eficientes, pois promoveriam a redução do lead-time; e eficazes, pois reduziriam determinados custos, com a eliminação de tarefas, bem como seriam reduzidas as incidências de falhas nos processos, tais como se pode observar na Tabela 3, a seguir:

Tabela 3 - Período Pré-Embarque (modelo proposto)

\begin{tabular}{|c|c|c|c|c|c|c|c|}
\hline Executor & Atividades & Dias & Min.gastos & $\begin{array}{l}\text { Horas } \\
\text { gastas }\end{array}$ & Direcionador & $\begin{array}{c}\text { Custo } \\
\text { direto } R \$\end{array}$ & Custo \\
\hline$E$ & 17 & \multirow[t]{4}{*}{7} & 510 & $8 \mathrm{hrs} 30 \mathrm{~min}$ & hora trabalho & 163,12 & Variável \\
\hline $\mathrm{R}$ & 0 & & 0 & 0 & $\begin{array}{c}\text { processo / } \\
\text { exp. }\end{array}$ & - & Fixo \\
\hline$A$ & 5 & & 120 & $2 \mathrm{hrs}$ & $\begin{array}{c}\text { processo / } \\
\text { exp. }\end{array}$ & 400,00 & Fixo \\
\hline$T$ & 3 & & 440 & $7 \mathrm{hrs} 20 \mathrm{~min}$ & peso & 500,00 & Variável \\
\hline Total & 25 & 7 & 1070 & 17hrs50min & & $1.063,12$ & \\
\hline
\end{tabular}

Fonte: Dados da Pesquisa (2009).

Mediante essa nova proposta, durante o período pré-embarque (Tabela 3), o exportador passou a executar 17 atividades alocadas em 8horas e 30 minutos (510 minutos), representando um custo de $\mathrm{R} \$ 165,12$, obtido pela redução do tempo para a realização das atividades. As atividades executadas pelo agente de cargas passaram de 3 para 5, originalmente alocadas em 70 minutos, passando para 120 minutos para a efetivação das mesmas. O valor dos serviços aeroportuários e a remuneração do agente de cargas permaneceram constantes ( $R \$ 400,00)$, visto que o valor da remuneração é fixado por processo, e independe de tempo ou atividades desempenhadas.

Com relação ao transporte rodoviário de entrega, o custo e o tempo para realização das atividades permaneceram constantes. Cabe a ressalva de que o valor de 
Redução de custos logísticos e lead time em operações de comércio exterior com a utilização do custeio baseado em atividades - ABC: Uma pesquisa-ação

Fábio Hiroshi Tomoyose, Ana Cristina de Faria, Paulo Sérgio Lopes Ruiz

$\mathrm{R} \$ 400,00$ cobrado pelo agente de cargas é a somatória das taxas aeroportuárias e a remuneração do serviço prestado pelo mesmo. Não foram cobrados a armazenagem e frete internacional, pois a configuração de um embarque FCA (Free Carrier) exige que o pagamento do frete seja realizado pelo importador (Collect). Com relação à taxa de armazenagem, caso esta seja mencionada no documento de embarque, será de responsabilidade do importador.

Tabela 4 - Período Pós-Embarque (modelo proposto)

\begin{tabular}{|c|c|c|c|c|c|c|c|}
\hline Executor & Atividades & Dias & Min.gastos & $\begin{array}{l}\text { Horas } \\
\text { gastas }\end{array}$ & Direcionador & $\begin{array}{c}\text { Custo } \\
\text { direto } R \$\end{array}$ & Custo \\
\hline$E$ & 2 & \multirow[t]{4}{*}{91} & 70 & $1 \mathrm{hrs} \mathrm{10min}$ & hora trabalho & 22,39 & variável \\
\hline$R$ & 0 & & 0 & 0 & $\begin{array}{l}\text { processo / } \\
\text { exp. }\end{array}$ & - & fixo \\
\hline C & 0 & & 0 & 0 & Valor/FOB & - & variável \\
\hline$B$ & 2 & & 30 & $30 \mathrm{~min}$ & $\begin{array}{l}\text { taxa por } \\
\text { operação }\end{array}$ & 100,00 & fixo \\
\hline Total & 4 & 91 & 100 & 1hrs40min & & 122,39 & \\
\hline
\end{tabular}

Fonte: Dados da Pesquisa (2009).

No período pós-embarque (Tabela 4), o Exportador passou a executar 2 atividades, alocadas em 70 minutos ao custo de $R \$ 22,39$; já os serviços de corretagem de câmbio e o processo de faturamento do despacho aduaneiro foram descartados e o Banco, que inicialmente era responsável por 1 atividade, passou a exercer 2 atividades, com tempo estimado de 30 minutos; ou seja, 20 minutos a mais que a configuração original apresentada para a efetivação das mesmas. A remuneração para este serviço permaneceu inalterada ( $R \$ 100,00)$, visto que as taxas são cobradas por fechamento de câmbio.

Conclui-se, por intermédio das Tabelas 3 e 4, e baseado na verticalização das atividades antes executadas pelo representante legal e a corretora de câmbio, que o custo da exportação aérea totalizou $R \$ 1.185,50$; apropriado a 29 atividades realizadas em $19 \mathrm{hs}$ e $30 \mathrm{~min}$. O lead time para a realização das atividades foi de 98 dias, 
Redução de custos logísticos e lead time em operações de comércio exterior com a utilização do custeio baseado em atividades - ABC: Uma pesquisa-ação

Fábio Hiroshi Tomoyose, Ana Cristina de Faria, Paulo Sérgio Lopes Ruiz

considerando na análise o período de 90 dias para a ocorrência do pagamento (contados a partir da data do embarque).

$\mathrm{Na}$ apuração dos resultados entre a configuração tradicional e a proposta, por meio da comparação das atividades, número de atividades e quantidade de dias necessários à execução das atividades e, principalmente, os custos inerentes, verificouse uma redução significativa entre o método anteriormente utilizado e o proposto. Verificou-se uma redução de $28 \%$ nas atividades e de $42 \%$ na quantidade de dias no período pré-embarque; $15 \%$ no período pós-embarque, redução do tempo em $36 \%$ e redução do custo em 43\%, conforme Tabela 5, a seguir:

Tabela 5 - Comparativos e Resultados das operações

\begin{tabular}{|c|c|c|c|c|c|c|c|c|}
\hline & Anterior & Proposto & Anterior & Proposto & Anterior & Proposto & $\begin{array}{c}\text { Anteri } \\
\text { or }\end{array}$ & Proposto \\
\hline Executor & Atividade & Atividade & Dias & Dias & Min.gasto & Min.gasto & $\begin{array}{c}\text { Custo } \\
\text { direto } \\
\mathbf{R} \$\end{array}$ & $\begin{array}{c}\text { Custo } \\
\text { direto } \\
\mathbf{R} \$\end{array}$ \\
\hline$E$ & 16 & 17 & \multirow{4}{*}{12} & \multirow{4}{*}{7} & 545 & 510 & 174,31 & 163,12 \\
\hline $\mathbf{R}$ & 6 & 0 & & & 455 & 0 & 750,00 & - \\
\hline A & 3 & 5 & & & 70 & 120 & 400,00 & 400,00 \\
\hline $\mathbf{T}$ & 3 & 3 & & & 440 & 440 & 500,00 & 500,00 \\
\hline $\mathbf{E}$ & 7 & 2 & \multirow[t]{4}{*}{107} & \multirow[t]{4}{*}{91} & 190 & 70 & 60,77 & 22,39 \\
\hline $\mathbf{R}$ & 1 & 0 & & & 30 & 0 & - & - \\
\hline C & 3 & 0 & & & 80 & 0 & 100,00 & - \\
\hline B & 1 & 2 & & & 10 & 30 & 100,00 & 100,00 \\
\hline Total & 40 & 29 & 119 & 98 & 1820 & 1170 & $\begin{array}{c}2.085 \\
08\end{array}$ & $1.185,50$ \\
\hline Redução & \multicolumn{2}{|c|}{$28 \%$} & \multicolumn{2}{|c|}{$18 \%$} & \multicolumn{2}{|c|}{$\frac{1}{36 \%}$} & \multicolumn{2}{|c|}{$43 \%$} \\
\hline
\end{tabular}

Fonte: Dados da Pesquisa (2009).

Supondo que a empresa realize 100 exportações durante o ano, com a mesma configuração proposta no modelo de redução de custos, o resultado seria $R \$ 90.000,00$ adicionais em receita, em descontos nas exportações realizadas, nas exportaçõeschave realizadas etc. Além da redução de cinco dias no lead time pré-embarque e dezesseis dias no pós-embarque para a mensuração dos custos, a metodologia apresentada reúne esforços com o objetivo de agregar valor por meio de um nível de 
Redução de custos logísticos e lead time em operações de comércio exterior com a utilização do custeio baseado em atividades - ABC: Uma pesquisa-ação

Fábio Hiroshi Tomoyose, Ana Cristina de Faria, Paulo Sérgio Lopes Ruiz

serviço de excelência, mas ao menor custo total possível, como condição de otimizar resultado econômico e continuidade da organização. Na sequência são tratadas as importações marítimas realizadas na empresa.

\subsection{As Importações marítimas da Nippon2}

Em Março de 2009 o gestor responsável pelo Departamento de Comércio Exterior da Nippon2 decide avaliar os esforços empreendidos no controle e redução dos custos logísticos inerentes à atividade de importar. A metodologia até então aplicada pela empresa na apuração dos custos logísticos de importação mostrou-se ineficiente, no sentido de não detalhar os lançamentos contábeis, foi incapaz de fornecer detalhes que possibilitassem a avaliação e controle dos mesmos. Diante disso, foram levantados todos os processos de importação do ano de 2008 e 2009 até o mês de maio, na tentativa da aplicação de uma metodologia capaz de relacionar custos com as atividades, ou seja, optou-se pela aplicação do conceito do Custeio Baseado em Atividades - ABC.

$\mathrm{Na}$ tentativa de uma avaliação dos custos logísticos de importação, que pudessem fornecer detalhes e, ao mesmo tempo, não influenciar decisões, devido à grande variedade de origens, sazonalidades, procedimentos, produtos, bem como a particularidade de cada importação, buscou-se o método de custeio mais adequado. Dentre os processos existentes, foram selecionadas importações de uma mesma origem, com mesmo fornecedor, com as mesmas características e realizadas em um mesmo período de anos diferentes, ou seja, o mês de Maio dos anos de 2008 e 2009.

Inicialmente, todas as características dos processos foram relacionadas em uma tabela, tais como o exportador; os portos de origem e destino; os prestadores de serviços envolvidos; as datas de embarque e chegada no destino; do registro da Declaração de Importação, do desembaraço aduaneiro e entrega da carga; canal de parametrização; tipo de embarque ( $F C L)$; método de desembaraço; quantidade de conhecimentos de embarque emitidos; formas de entrega; peso líquido e bruto; cubagem; tipo de volume; quantidade de volumes; taxas de câmbio; valor FOB das 
Redução de custos logísticos e lead time em operações de comércio exterior com a utilização do custeio baseado em atividades - ABC: Uma pesquisa-ação

Fábio Hiroshi Tomoyose, Ana Cristina de Faria, Paulo Sérgio Lopes Ruiz

mercadorias; impostos incidentes e os custos logísticos, de modo que todas as etapas, atividades e custos pudessem ser analisados.

Todas as atividades inerentes às operações foram mapeadas e tiveram mensurados os seus respectivos custos, com o objetivo de apurar-se o custo total das operações e obter visibilidade das atividades como um todo. Por intermédio da apuração das características, bem como o mapeamento das atividades e os seus respectivos custos, verificou-se que nos anos de 2008 e 2009 as importações realizadas no período de maio apresentavam configurações semelhantes, tais como fornecedor, origem, produtos, datas de embarque e chegada, embarques em contêineres de 20' (vinte pés), bem como a opção por desembaraços em lotes, ou seja, para um único embarque (master) eram emitidos três conhecimentos de embarque (houses).

Com relação à importação realizada em maio de 2008, apurou-se um transit time de 32 dias (entre período de embarque e chegada no porto de destino); um período de 20 dias contados a partir da chegada da mercadoria no porto até o desembaraço da carga em Zona Secundária e um período de 3 dias contados da data do desembaraço ao dia da entrega nas instalações da empresa, resultando em um lead time de 56 dias contados da data do embarque à data de entrega das mercadorias.

Referente aos volumes carregados no container, os mesmos somavam o equivalente a $10,18 \mathrm{~m}^{3}$, com peso bruto de $1.721,00 \mathrm{Kgs}$, sendo a capacidade cúbica de um container standard de 20' (vinte pés) o equivalente a $33,2 \mathrm{~m}^{3}$, podendo suportar até $21.920,00 \mathrm{Kgs}$ de carga. Em outras palavras, houve um desperdício de 23,0 $\mathrm{m}^{3}$ de espaço e 20.000,00 Kgs de peso, que poderiam ter sido carregados, sem que houvesse custos adicionais no valor do frete, uma vez que o valor para cargas FCL (container cheio) é fixado por unidade de container, em que é possível estufá-lo até o limite de sua capacidade, por um valor único.

$\mathrm{Na}$ análise dos custos decorrentes desta operação, verificou-se em 2006 que $12,76 \%$ do valor FOB das mercadorias representavam os custos logísticos; $18,48 \%$ o imposto de importação (não recuperável) e $72,88 \%$ os impostos recuperáveis (IPI, PIS, 
Redução de custos logísticos e lead time em operações de comércio exterior com a utilização do custeio baseado em atividades - ABC: Uma pesquisa-ação

Fábio Hiroshi Tomoyose, Ana Cristina de Faria, Paulo Sérgio Lopes Ruiz

COFINS e ICMS), somando um custo total de $104,12 \%$ do valor FOB das mercadorias. O resultado da análise preliminar reforçou a ideia de que seria necessário empreender esforços na redução de custos e lead time das importações. Dessa forma, foram adotadas medidas como a análise estatística das importações parametrizadas em Canal Vermelho, pesquisas de leis, decretos e portarias; a análise dos serviços prestados e a renumeração dos mesmos, por meio dos Indicadores-Chave de Desempenho (KPIs). Segundo Gasparetto e Bornia (2002), estes indicadores são medidas de diagnóstico, pois monitoram as operações, indicando o momento em que fatos incomuns afetam os processos (falhas, perdas anormais).

Com base na verificação estatística das importações em maio de 2009, foi possível a eliminação da etapa de remoção de Zona Primária para Zona Secundária e a consequente eliminação dos custos decorrentes desta operação, visto que $94 \%$ das importações realizadas eram parametrizadas em Canal Verde (Liberadas sem Conferência Física ou Documental) e com respaldo legal foi possível aderir à modalidade de desembaraço "Parte Lote", ou seja, a nacionalização da carga em lotes; dessa vez sem que houvesse a desova do container.

O desembaraço "Parte Lote" em Zona Primária, com a re-destinação do container para outro terminal, e sem a ocorrência da desova do mesmo, foi capaz de eliminar totalmente os custos de remoção (DTA), de transporte rodoviário para a remoção de zona primária para zona secundária, do frete rodoviário de entrega da zona secundária para a fábrica, das despesas de armazenagem, movimentação e seguro em zona secundária; SDA (Sindicato dos Despachantes Aduaneiros) recolhida para serviços de remoção; bem como redução no custo de remuneração de serviços aduaneiros e de movimentação e armazenagem em Zona Primária.

Mediante a aplicação de simples medidas, verificou-se em 2009 uma redução de $21 \%$ dos custos logísticos, em comparação ao mesmo período do ano de 2008 , e uma redução de 5,39\% entre os índices apresentados em relação aos valores FOB das mercadorias, que representavam $12,76 \%$ em 2008, passando a representar $7,37 \%$ em 2009. Cabe ressaltar a redução em 9 dias do lead time total, passando de 56 dias em 
Redução de custos logísticos e lead time em operações de comércio exterior com a utilização do custeio baseado em atividades - ABC: Uma pesquisa-ação

Fábio Hiroshi Tomoyose, Ana Cristina de Faria, Paulo Sérgio Lopes Ruiz

2006 para 47 dias em 2009. Não obstante ao resultado apresentado, entre perdas e ganhos, concluiu-se que o resultado final apresentou-se insatisfatório, visto que o custo final de fato foi reduzido; porém em função de detalhes pertinentes às operações logísticas e a manutenção dos prestadores de serviços envolvidos, o resultado final foi tímido. Dessa forma, concluiu-se que seria necessário o empreendimento de novos esforços no alcance da minimização total dos custos.

O gestor responsável, já contando com uma redução de $21 \%$ dos custos logísticos, decidiu avaliar o nível de importância de cada custo, e concluiu que o custo do transporte internacional representou a maior parcela dos custos logísticos, com $31,55 \%$ do total. Diante do desafio de reduzir custos, foram levados em consideração os principais fatores que influenciam e impactam diretamente nos custos de transporte que, de acordo com Bowersox, Closs e Cooper (2002, p.356) são: distância, volume, densidade, facilidade de acondicionamento, facilidade de manuseio, responsabilidade e mercado.

$\mathrm{Na}$ busca por uma melhor decisão de transporte, em termos de custos, a Nippon2 verificou mediante pesquisa de preços no mercado de fretes internacionais, que uma negociação diretamente com o armador tornaria viável o objetivo de reduzir seus custos logísticos, visto que a partir desta negociação direta arcaria somente com os custos da locação do container e taxas locais no destino, eliminando a remuneração de intermediários (Freight Forwards). Para tanto, a empresa deveria optar pelo embarque único do container, eliminando o desembaraço das mercadorias em lotes, visto que não cabe ao armador, mas sim aos seus intermediários, a desconsolidação, ou seja, as mercadorias passariam a ser embarcadas por meio da emissão de apenas um conhecimento de embarque marítimo ( $B / L$ Master) que, consequentemente, resultaria em apenas um desembaraço.

Não obstante a uma negociação de frete diretamente com o armador, que de fato proporcionaria uma redução significativa no custo total do frete, deve-se levar em consideração a relação entre peso e volume. Pode-se verificar com base na configuração do embarque realizado em 2009, de que seria viável um embarque $L C L$ 
Redução de custos logísticos e lead time em operações de comércio exterior com a utilização do custeio baseado em atividades - ABC: Uma pesquisa-ação

Fábio Hiroshi Tomoyose, Ana Cristina de Faria, Paulo Sérgio Lopes Ruiz

(Less Than a Container Load), em vez de FCL (Ful Container Load); visto que conforme supracitado foram apresentados desperdícios de cubagem e peso, de acordo com a capacidade do container.

Diante da configuração de um embarque $L C L$, definido por Wood et al. (2002, p. 91), como uma fração do container cheio, deve-se levar em consideração os fatores de tempo e risco na decisão de um embarque nesta modalidade, em função da desconsolidação, desova, armazenagem e riscos de avaria e roubo da carga. É importante considerar que no transporte internacional o valor do frete impacta diretamente nos custos de armazenagem, taxa de AFRMM (Adicional ao Frete para a Renovação da Marinha Mercante), transporte rodoviário de entrega e nos impostos incidentes sobre as importações. Com a redução do custo do transporte internacional, consequentemente, os custos mencionados seriam reduzidos.

Em face das propostas apresentadas, conclui-se que a proposta de frete inicialmente utilizada em 2009 poderia ser descartada, surgindo opções ou por um embarque FCL (Full Container Load) contratando o frete diretamente com o armador, ou um embarque LCL (Less Than a Container Load) utilizando-se outro agente consolidador, em função dos valores apresentados, que como já mencionado impactam diretamente em outros custos.

Com relação aos serviços prestados no desembaraço aduaneiro de importação, verificou-se que os valores dos honorários cobrados em 2009, com base no valor CIF (Cost, Insurance and Freight), não correspondiam à realidade, visto que os serviços cobrados por outros prestadores utilizavam como base um valor fixo por desembaraço, com valores diferenciados entre os pesquisados, o que resultou na decisão da utilização de serviços de outro prestador. Optou-se por um operador logístico baseado em informação e gestão, que permitisse identificar e implantar as melhores soluções, conforme destaca Fleury (2007) na definição do operador logístico. Na avaliação dos demais custos foram apuradas as relevâncias na decisão por embarques $F C L$ (container cheio) ou LCL (Carga Solta), conforme Tabela 6, a seguir: 
Redução de custos logísticos e lead time em operações de comércio exterior com a utilização do custeio baseado em atividades - ABC: Uma pesquisa-ação

Fábio Hiroshi Tomoyose, Ana Cristina de Faria, Paulo Sérgio Lopes Ruiz

Tabela 6 - Relação entre embarques FCL vs LCL

\begin{tabular}{|c|c|c|c|}
\hline DESCRIÇÃO DO CUSTO & EMB (FCL) & EMB (LCL) & VARIAÇÃO \\
\hline AFRMM - 25\% sobre Frete & $-482,34$ & 292,55 & $39,35 \%$ \\
\hline Frete Rodov. Santos/NIPPON 2 & $-1.704,93$ & $1.455,78$ & $14,61 \%$ \\
\hline Armazenagem Zona Primária & 585,36 & $-1.068,97$ & $45,24 \%$ \\
\hline Movimentação Zona Primária & 319,69 & $-488,69$ & $34,58 \%$ \\
\hline
\end{tabular}

Fonte: Dados da Pesquisa (2009).

$\mathrm{Na}$ comparação apresentada na Tabela 6 em relação ao Adicional de Frete para a Renovação da Marinha Mercante (AFRMM), verificou-se que a decisão por um embarque $L C L$ contribuiria para a redução de 39,35\% em comparação a um embarque FCL. O custo do frete rodoviário de entrega em um embarque $L C L$, contribuiria para uma redução de $14,61 \%$ em comparação a uma decisão por um embarque $F C L$. No que tange ao custo de armazenagem em zona primária, verificou-se que um embarque $F C L$, ao contrário de um embarque $L C L$, contribuiria para uma redução de $45,24 \%$. Observou-se ainda neste item, que a economia nos custos em um embarque $L C L$ poderia ser compensada com o aumento do valor da armazenagem, ou seja, ocorreria um trade off; em que os valores de frete internacional e demais custos logísticos seriam reduzidos; porém, o custo de armazenagem seria 45,24\% maior na modalidade $L C L$. No custo de movimentação em zona primária, observou-se que em um embarque $F C L$, ao contrário de um embarque $L C L$, contribuiria para uma redução de 34,58\%, merecendo destaque como fator relevante para a ocorrência de um trade off.

Diante dos custos logísticos totais apurados, com base na aplicação de uma nova metodologia, foram verificadas novas alternativas que direcionaram o pensamento à minimização total dos custos, com respaldo legal e foco nas atividades logísticas, que viabilizaram as seguintes alternativas e mudanças:

- Troca de modalidade de desembaraço, na qual se admitia "part lof", passando para modalidade comum, por meio da emissão de apenas um B/L, com respaldo legal; 
Redução de custos logísticos e lead time em operações de comércio exterior com a utilização do custeio baseado em atividades - ABC: Uma pesquisa-ação

Fábio Hiroshi Tomoyose, Ana Cristina de Faria, Paulo Sérgio Lopes Ruiz

- Avaliação dos preços de mercado dos serviços prestados no desembaraço aduaneiro, no agenciamento de cargas internacionais e de terminais localizados em Zona Primária de importação, na qual se verificou uma discrepância de valores oferecidos, variando de prestador para prestador;

- Eliminação de etapas desnecessárias, tais como as remoções para Zona Secundária e os custos decorrentes delas, bem como frete rodoviário, serviço de DTA (Declaração de Trânsito Aduaneiro), S.D.A. (Sindicato dos Despachantes Aduaneiros), Armazenagem em Zona Secundária, Movimentação em Zona Secundária e seguro, além da redução do lead time, e

- Decisão de embarque: se um embarque $F C L$ ou $L C L$, e a influência desta nos demais custos e, consequentemente, no custo logístico e no lead time total.

Com base na nova configuração, verificou-se uma redução de $48,68 \%$ no custo logístico total, em comparação com os custos totais apresentados em 2009, para a decisão de um embarque FCL (Contêiner Cheio) e uma redução de 52,52\% para a decisão de um embarque LCL (Carga Solta /Consolidada), conforme Tabela 7:

Tabela 7 - Relação entre embarques FCL vs LCL

\begin{tabular}{|c|c|c|c|}
\hline CUSTOS LOGÍSTICOS & $\mathbf{2 0 0 9}$ & $\begin{array}{c}\text { EMBARQUE } \\
\text { FCL }\end{array}$ & $\begin{array}{c}\text { EMBARQUE } \\
\text { LCL }\end{array}$ \\
\hline Custos Logísticos Totais & $14.179,57$ & $7.277,28$ & $6.732,86$ \\
\hline Redução para embarque FCL & \multicolumn{3}{|c|}{$48,68 \%$} \\
\hline Redução para embarque LCL & \multicolumn{3}{|c|}{$52,52 \%$} \\
\hline
\end{tabular}

Fonte: Dados da Pesquisa (2009).

Com relação ao Imposto de Importação (não recuperável em termos fiscais) e que se caracteriza como um custo logístico efetivamente incorrido na operação, apurouse uma redução de 1,28\% em relação a 2007; para uma decisão de embarque $F C L$, e uma redução de $1,67 \%$ para uma decisão de embarque $L C L$, conforme se pode observar na Tabela 8, a seguir: 
Redução de custos logísticos e lead time em operações de comércio exterior com a utilização do custeio baseado em atividades - ABC: Uma pesquisa-ação

Fábio Hiroshi Tomoyose, Ana Cristina de Faria, Paulo Sérgio Lopes Ruiz

Tabela 8 - Tributos Não Recuperáveis nas operações (Custos)

\begin{tabular}{|c|c|c|c|}
\hline $\begin{array}{c}\text { TRIBUTOS NÃO } \\
\text { RECUPERÁVEIS }\end{array}$ & 2009 & $\begin{array}{c}\text { EMBARQUE } \\
\text { FCL }\end{array}$ & $\begin{array}{c}\text { EMBARQUE } \\
\text { LCL }\end{array}$ \\
\hline Imposto de Importação & $35.577,96$ & $35.121,63$ & $34.984,43$ \\
\hline $\begin{array}{c}\text { Redução para embarque } \\
\text { FCL }\end{array}$ & \multicolumn{2}{|c|}{$1,28 \%$} & \\
\hline $\begin{array}{c}\text { Redução para embarque } \\
\text { LCL }\end{array}$ & \multicolumn{3}{|c|}{$1,67 \%$} \\
\hline
\end{tabular}

Fonte: Dados da Pesquisa (2009).

Para os impostos recuperáveis (IPI, PIS, COFINS e ICMS), verificou-se uma redução de $1,28 \%$ em relação a 2009 , para uma decisão de embarque $F C L$, e uma redução de 1,67\% para uma decisão de embarque $L C L$, conforme Tabela 9, a seguir:

Tabela 9 - Tributos Recuperáveis nas operações

\begin{tabular}{|c|c|c|c|}
\hline TRIBUTOS RECUPERÁVEIS & 2009 & $\begin{array}{c}\text { EMBARQUE } \\
\text { FCL }\end{array}$ & $\begin{array}{c}\text { EMBARQUE } \\
\text { LCL }\end{array}$ \\
\hline IPI, PIS, COFINS e ICMS & $140.333,12$ & $138.533,72$ & $137.992,74$ \\
\hline Redução para embarque FCL & \multicolumn{3}{|c|}{$1,28 \%$} \\
\hline Redução para embarque LCL & \multicolumn{3}{|c|}{$1,67 \%$} \\
\hline
\end{tabular}

Fonte: Dados da Pesquisa (2009).

Em relação ao Lead Time constatou-se uma redução de oito dias para a decisão de um embarque $F C L$ e de quatro dias para a decisão de um embarque $L C L$, justificados pela implantação da Nota Fiscal Eletrônica, que eliminou a etapa de emissão da Nota Fiscal de Entrada em formulário impresso, podendo esta ser enviada por meio eletrônico. Não obstante ao resultado proposto, para a minimização dos custos no tocante à logística internacional, é importante ressaltar que a empresa também poderá obter ganhos significativos com os custos tributários incidentes nas operações de importação, se analisados os benefícios fiscais e a utilização de Regimes Aduaneiros Especiais - Decreto 6759/2009 (BRASIL, 2013). 
Redução de custos logísticos e lead time em operações de comércio exterior com a utilização do custeio baseado em atividades - ABC: Uma pesquisa-ação

Fábio Hiroshi Tomoyose, Ana Cristina de Faria, Paulo Sérgio Lopes Ruiz

Com a definição dos direcionadores de cada custo, foi possível simular e definir uma nova configuração para os embarques da empresa Nippon2, que segundo os indicadores obtidos passaram a representar uma economia, na seguinte ordem:

Tabela 10 - Comparativo final entre embarques FCL vs LCL

\begin{tabular}{|c|c|c|}
\hline DESCRIÇÃO & $\begin{array}{c}\text { EMBARQUES } \\
\text { (FCL) }\end{array}$ & $\begin{array}{c}\text { EMBARQUES } \\
\text { (LCL) }\end{array}$ \\
\hline Custo Logístico Total & $(48,68 \%)$ & $(52,52 \%)$ \\
\hline Imposto de Importação & $(1,28 \%)$ & $(1,67 \%)$ \\
\hline IPI, PIS, COFINS e ICMS & $(1,28 \%)$ & $(1,67 \%)$ \\
\hline Lead Time & 8 dias & 4 dias \\
\hline
\end{tabular}

Fonte: Dados da Pesquisa (2009).

Houve redução de $48,68 \%$ no Custo Logístico Total para embarques FCL e de $52,52 \%$ para embarques LCL. No que diz respeito ao Imposto de Importação houve redução de 1,28\% para embarques FCL e de 1,67\% para embarques LCL. Em termos tributários, no IPI, PIS, COFINS e ICMS houve redução de 1,28\% para embarques FCL e de $1,67 \%$ para embarques LCL. No que tange ao Lead Time, ocorreu redução de 8 dias para embarques FCL e de 4 dias para embarques LCL.

Diante do trabalho desenvolvido pelos pesquisadores, conjuntamente com os gestores da Empresa Nippon2, pode-se concluir que a aplicação do método do Custeio Baseado em Atividades foi útil para a efetiva redução de custos logísticos e lead times nos processos de importação e exportação, com a utilização dos recursos disponíveis e sem necessidades de investimentos.

\section{CONSIDERAÇÕES FINAIS}

Este trabalho tem como objetivo verificar como podem ser reduzidos os custos logísticos e o lead-time nas operações de importação e exportação, dispondo dos recursos disponíveis e sem qualquer tipo de investimento. Por meio da Pesquisa-Ação focalizada nas exportações aéreas e importações marítimas da Empresa Nippon2, 
Redução de custos logísticos e lead time em operações de comércio exterior com a utilização do custeio baseado em atividades - ABC: Uma pesquisa-ação

Fábio Hiroshi Tomoyose, Ana Cristina de Faria, Paulo Sérgio Lopes Ruiz

conclui-se que dentro do universo das operações globais pertinentes às exportações e importações, com a utilização do método do Custeio Baseado em Atividades - ABC é possível obter reduções significativas de custos, eliminando desperdícios, redirecionando recursos mal empregados, mapeando as atividades e processos, e conhecendo intimamente cada atividade e o fluxo de suas informações; bem como aplicando e definindo na íntegra os direcionadores dos custos inerentes a estas atividades.

O mapeamento das atividades e a identificação dos custos atrelados a estas, proporcionaram a identificação das causas dos elevados custos e a avaliação das atividades atreladas aos mesmos, com o objetivo da otimização dos recursos empreendidos. A análise dos preços de mercado na prestação de serviços em comércio exterior (despacho aduaneiro e armazenagem) e transporte internacional, também foram essenciais na definição de um preço médio oferecido por este mercado de serviços, e reforçou a ideia de que seriam necessárias medidas de correção para as discrepâncias apresentadas. Conhecidas as causas da geração dos elevados custos, foi possível propor uma nova configuração para os embarques de exportação aérea e importação marítima da empresa Nippon2.

No caso das exportações, a configuração proposta consistiu basicamente na verticalização de determinadas atividades, passando a ser exercidas pela própria empresa, como a confecção dos REs (Registros de Exportação) e DE (Declaração de Exportação) em nome da própria empresa, bem como o fechamento de câmbio diretamente com o Banco, sem a intermediação da corretora de câmbio, representando uma economia de 11 atividades, 21 dias de lead time (entre recebimento do pedido e liquidação do câmbio de exportação) e 43\% de custos logísticos na exportação, para a configuração do objeto da análise. Ao contrário do que se imaginou inicialmente, as mudanças não ocasionaram trade-offs, ou seja, as alterações não diminuíram os custos de um lado e aumentaram de outro, ao contrário, realmente houveram reduções conforme comprovado. 
Redução de custos logísticos e lead time em operações de comércio exterior com a utilização do custeio baseado em atividades - ABC: Uma pesquisa-ação

Fábio Hiroshi Tomoyose, Ana Cristina de Faria, Paulo Sérgio Lopes Ruiz

Em relação às importações, a configuração proposta consistiu na mudança total da configuração originalmente empregada pela Nippon2, que obteve reduções com a aplicação do método do Custeio Baseado em Atividades; porém, devido à complexidade do custeio e as atividades, bem como uma análise falha dos direcionadores de custos, não contribuíram para o resultado esperado. Não bastou o remanejamento dos prestadores envolvidos; houve a necessidade de uma análise integral das atividades e dos custos, e a definição exata dos direcionadores, bem como o pleno conhecimento da influência de determinados custos em outros.

Como exemplo, o custo do transporte internacional que impacta diretamente na apuração dos impostos recuperáveis e não recuperáveis; Adicional de Frete para Renovação da Marinha Mercante (AFRMM); transporte de entrega; seguro e armazenagem. No caso das importações, a empresa deveria definir parâmetros para embarque, se $F C L$ ou $L C L$, pois a decisão de uma ou de outra poderia impactar diretamente em outros custos. Por exemplo, no caso de um embarque LCL, poderia apurar-se um custo menor de frete internacional; porém, os custos de armazenagem, da entrega, da movimentação e o lead-time seriam maiores, ou seja, a decisão de um ou de outro, que se não avaliados corretamente, ocasionariam trade-offs.

Recomenda-se que futuros trabalhos possam analisar os impactos nos custos logísticos e lead times em operações de importação e exportação com a utilização de programas e regimes especiais, tais como Fundo para o Desenvolvimento das Atividades Portuárias - FUNDAP e o Regime Aduaneiro Especial de Entreposto Industrial sob Controle Informatizado - RECOF.

\section{REFERÊNCIAS}

ATKINSON, A.A. et al. (2000). Contabilidade Gerencial. São Paulo: Atlas.

BOWERSOX, D. F.; CLOSS, D. J.; COOPER, B.M. (2002). Supply chain logistics management. New York: McGraw-Hill. 
Redução de custos logísticos e lead time em operações de comércio exterior com a utilização do custeio baseado em atividades - ABC: Uma pesquisa-ação

Fábio Hiroshi Tomoyose, Ana Cristina de Faria, Paulo Sérgio Lopes Ruiz

BRASIL. Decreto 6759, de 05 de Fevereiro de 2009, Livro II, Título I, Capítulo I. Disponível em: <http://www.receita.fazenda.gov.br/Legislacao/Decretos/2009/dec6759.htm> Acesso em 02/Dez/2013.

CARBAUGH, R.J. (2004). Economia Internacional. São Paulo: Pioneira Thompson Learning.

FARIA, A. C.; COSTA, M. F. G. (2005). Gestão de custos logísticos: custeio baseado em atividades ( $A B C)$, Balanced Scorecard (BSC), valor econômico agregado (EVA). São Paulo: Atlas.

FENDER, M.; KOUVELIS, P.; DORNIER, P.-P.; Ernst, R. (2000). Logística e Operações Globais: Textos e casos. São Paulo: Atlas.

FLEURY, P. F.; WANKE, P.; FIGUEIREDO, K. F. (2007). Logística empresarial. São Paulo: Atlas.

GASPARETTO, V.; BORNIA, A. C. (2002). O Balanced Scorecard como uma Ferramenta de Feedback e Aprendizado Estratégico. Anais... São Paulo: IX Congresso Brasileiro de Custos.

HORNGREN, C.T.; FOSTER, G.; DATAR, S. M. (2000) - Contabilidade de Custos. LTC. (9 ed.). Rio de Janeiro.

KAPLAN, Robert S. et al. (1998). Advanced Management Accounting. NY: Prentice-Hall.

KEEGAN, W. J.; GREEN, M.C. (2000). Princípios de Marketing Global. São Paulo: Saraiva.

KOTABE, M.; HELSEN, K. M. (2009). Global Marketing Management. Journal of Global Marketing. V.22, No. 4.

LAMBERT, D. M.; STOCK, J. R.; VANTINE, J. G. (1998). Administração estratégica da logística. Tradução de Maria Cristina Vondrak. São Paulo: Vantine Consultoria.

LOPEZ, J. M. C. (2000). Os Custos Logísticos do Comércio Exterior Brasileiro. São Paulo: Aduaneiras.

Aduaneiras.

; GAMA, M. (2002). Comércio exterior competitivo. São Paulo: 
Redução de custos logísticos e lead time em operações de comércio exterior com a utilização do custeio baseado em atividades - ABC: Uma pesquisa-ação

Fábio Hiroshi Tomoyose, Ana Cristina de Faria, Paulo Sérgio Lopes Ruiz

MALUF, S. N. (2003). Administrando o Comércio Exterior do Brasil. São Paulo: Aduaneiras.

MARTINS, E. (2003). Contabilidade de Custos. (9 ed.). São Paulo: Atlas.

MARTINS, G. de A. (2006). Estudo de Caso: uma estratégia de pesquisa. São Paulo: Atlas.

MDIC - Ministério do Desenvolvimento, Indústria e Comércio Exterior. Disponível em: $<$ http://www.mdic.gov.br//sitio/interna/interna.php?area=5\&menu=246>. Acessado em 02/Dez/2013.

RATTI, B. (1994). Comércio internacional e câmbio. (8 ed.). São Paulo: Aduaneiras.

RICHARDSON, R. J. (2007). Pesquisa social: métodos e técnicas. (3 ed.). São Paulo: Atlas.

ROCHA, P. C. A. (2003). Logística \& Aduana. (3 ed.). São Paulo:Aduaneiras, 2008.

RODRIGUES, W. Comércio Exterior: Incoterms: operacionalização e prática. Campinas: Alínea.

SEVERINO, A. J. (2007). Metodologia do trabalho científico. (23 ed.). rev. e ampl. São Paulo: Cortez.

THEMIDO, I.; ARANTES, A.; FERNANDES, C.; GUEDES, A. P. (2000). Logistics costs case study - an ABC approach. Journal of the Operational Research Society. Vol. 51, No. 10.

THIOLLENT, M. (2000). Metodologia da Pesquisa-Ação. (11 ed.). São Paulo: Cortez.

THORSTENSEN, V. (2003). OMC: organização mundial do comércio, as regras do comércio internacional e a nova rodada de negociações multilaterais. (2 ed.). São Paulo: Aduaneiras.

VASCONCELLOS, M. A. S. de. (2000). Economia: micro e macro. São Paulo: Atlas.

WOOD, D. F.; BARONE, A.P.; MURPHY, P. R.; WARDLOW, D. L. (2002). International Logistics. (2 ed.). New York: Amacom.

Data de Submissão: 02/12/2013

Data de Aceite: 17/03/2014 